\title{
Debt-equity choice as a signal of earnings profile over time*
}

\author{
Anton Miglo ${ }^{\dagger}$
}

2006.

\begin{abstract}
This paper analyzes the debt-equity choice for financing a two-stage investment when a firm's insiders have private information about the firm's expected earnings. When private information is one-dimensional (for example when short-term earnings are common knowledge while long-term earnings are private information) a separating equilibrium does not exist. When private information is two-dimensional a separating equilibrium may exist where firms with a higher rate of earnings growth issue debt and firms with a low rate of earnings growth issue equity. This provides new insights into the issue of different kinds of securities by different types of firms under asymmetric information as well as the link between debtequity choice and operating performance.
\end{abstract}

Keywords: Debt-equity choice, Asymmetric information, Timing of earnings, Long-term underperformance

JEL Classifications: D82, D92, G24, G32

${ }^{*}$ This article is an extensively revised version of ch. 2 of my Ph.D thesis. I am grateful to Bram Cadsby, Jean Cossette, Georges Dionne, Mike Hoy, Pierre Lasserre, Deborah Lucas, Robert McDonald, Nicolas Marceau, A. Nejadmalayeri, Stephane Pallage, Michel Robe, Urs Schweizer and especially Claude Fluet and Thomas Noe for usefull suggestions and comments on earlier versions of this paper. Also many thanks to seminar participants at the University of Guelph, ESADE, University of Bonn, UQAM, the Bank of Canada, the 2003 MidWest Finance Association meetings, the 2002 CIRPEE conference, the 2003 SCSE meetings, the 2003 International Congress of the French Finance Association, the 2003 German Finance Association meetings. The financial support awarded by the Social Sciences and Humanities Research Council of Canada and the Institut de finance mathématique de Montréal was instrumental in enabling our continued research. I also appreciate the editing assistance of Chris Mitchell, Peter Huffman and Kaarla Sundström.

$\dagger^{\dagger}$ University of Guelph, Department of Economics, Guelph, Ontario, Canada, N1G 2W1, tel. (519) 824-4120, ext. 53054, email: amiglo@uoguelph.ca 


\section{Introduction}

This paper analyzes debt-equity choice when asymmetric information exists between firms' insiders and market participants regarding future earnings. Most existing literature deals with one-dimensional asymmetric information-most frequently concerning the value of the firm. In this approach the solution is typically a pooling equilibrium where the "bad" type (one with low value) mimics the "good" type (one with high value) by issuing the same kind of securities. A "second effort" (additional assumptions) is needed to explain why firms issue securities that are not a part of the equilibrium.

In the present paper, we analyze a signaling game where private information is two-dimensional: the insiders have private information about the amounts and timing of future earnings. ${ }^{1}$ Asymmetric information about the timing of earnings may take place because: 1) managers may have private information about the choice of inventory and depreciation methods, allowance for bad debts, expensing of research and development, recognition of sales not yet shipped, estimation of pension liabilities, capitalization of leases and marketing expenses, delay in maintenance expenditures and delay in production; 2) managers may be subject to moral hazard problems which affect the intensity and productivity of their efforts over time and; 3) corporations typically employ long-term strategic planning, giving insiders private information for several years.

We analyze a two-stage investment-financing model where managers representing initial shareholders have the choice between debt (short- and long-term) and equity. When only the total earnings are private information, and the timing of earnings is common knowledge, the equilibrium is pooling. However, when both the value of the firm and the timing of earnings is management's private information a separating equilibrium may exist. The following explains the main ideas behind the separating equilibrium. First, it is well known that in a separating equilibrium each financing strategy is chosen by the worst possible type of firm for that strategy (from the investor's viewpoint). ${ }^{2}$ Otherwise the firm will be mimicked by other firms which will benefit from the overvaluation of issued securities. We show that the value of shares depends on the firm's total value and not on the timing of earnings or on the rate of earnings growth; the value of long-term debt relies on the expected performance in the long term and the value of short-term debt depends primarily on the expected performance in the short term. If a firm with a high rate of earnings growth issues long-term debt it will be mimicked because of high expected long-term performance which implies a high value of long-term debt respectively. The same holds if the firm issues equity. Other firms may find it attractive to mimic this strategy not necessarily because of the high value of equity but because of the high value of future claims which the firm will issue in the long term. Thus, if the firm with

\footnotetext{
${ }^{1}$ In a similar spirit, some scholars assume that insiders have private information about the riskiness of their cash flows. See, for example, the second part of Brennan and Kraus (1987), Brick, Frierman and Kim (1998), Grinblatt and Hwang (1989) and Giammarino and Neave (1982).

${ }^{2}$ Brennan and Kraus (1987).
} 
a high rate of earnings growth and low short-term earnings respectively tries to separate itself in equilibrium it would do better to issue claims with the value depending primarily on short-term expected performance (short-term debt).

The main engine driving the results of the paper is that a separating equilibrium exists where firms with low rates of earnings growth issue equity. This equilibrium implies that firms issuing equity have better operating performance at the moment of issue or in the near future after issue, and that these firms have lower operating performance in the long run. The long run operating underperformance of equity issuing firms has been documented in several studies. This phenomenon is characterized by Ritter and Welch (2002) as the most controversial area of IPO (initial public offering) research. Whereas only a few studies support the efficient market point of view, others argue in favor of a behavioral point of view. ${ }^{3}$ The superior absolute performance of equity issuing firms immediately after the issue is, to our knowledge, a relatively new theoretical point. ${ }^{4}$ In contrast to the well-documented fact that firms issuing equity have higher performance just before the issue, their higher absolute performance immediately after the issue has not been a major point of empirical research (though it seems to be consistent with some empirical evidence). According to Jain and Kini (1994, Figure 1) the operating return on assets is higher for IPO firms in the first years after the issue and the operating cash flow on assets is higher in year "0" (immediately after issue). In Loughran and Ritter (1997) profit margins are higher in years 0 and +1 , although there is different evidence about operating returns. In Mikkelson, Partch and Shah (1997, Table 3) IPO firms have higher performance in year 0 .

The model also generates new predictions which have not been tested in existing literature. In particular, we study how the following factors affect the conditions of existence for separating equilibrium: bankruptcy costs (reorganization costs), the extent of asymmetric information regarding firms' values and the timing of earnings. For example, we argue that the emergence of separating equilibrium and phenomena such as long-term underperformance of firms issuing equity are more probable when the extent of asymmetric information regarding the timing of earnings is relatively large and that regarding total earnings is relatively small. When the difference between firms' total values is large enough a separating equilibrium does not exist because the type with a low total value will mimic the high value type. On the other hand, a large difference in the firms' rates of earnings growth contributes to the existence of a separating equilibrium by making it possible for a firm to design debt claims which will not be mimicked by other firms. We provide a discussion of possible strategies for testing this result.

\footnotetext{
${ }^{3}$ When speaking about long run performance, Ritter and Welch (2002) incorporate all aspects of this problem and not specifically the afterissuing underperformance of firms that issue equity, although this aspect is a part of their analysis.

${ }^{4}$ Most analysts conclude that issuing firms underperform non-issuing firms in the first few years after issue. The undeperformance is measured by the performance after issue relative to the performance in the year before the issue. This does not contradict the fact that these firms my have higher absolute performance immediately after issue.
} 
The model in the present paper is closely related to the "pecking-order theory" put forward by Myers and Majluf (1984). They consider a single-stage investment model in which asymmetric information exists about the value of both assets in place and the new project. ${ }^{5}$ While it provides many important insights into firm behavior under asymmetric information, most notably the underinvestment problem and why firms may prefer internal financing to external financing, it does not explain why firms issue equity. Myers (1984) argues that when firms have dividend ratio constraints or external debt constraints, they may issue equity. However, some research demonstrates that firms issue equity even when they are not financially constrained (see, for instance, Loughran and Ritter, 1997).

Lucas and McDonald (1990) also analyze firms' incentives to issue equity under asymmetric information. If a firm requires funding for a project that has a long-term decision horizon and a delay in accepting the project has low cost, then an undervalued firm will choose to delay issuing equity until the true value of the firm is revealed and the share price rises. Thus, the paper explains why, on average, positive abnormal returns will precede equity issues and why decreases in stock prices often accompany stock issue announcements while it is not focused on the correlation between debt and profitability and on operating performance after issue.

Our model is also related to Goswami, Noe and Rebello (1995) where a firm's managers have long term private information about the firm's quality. This paper focuses on the debt maturity choice. The absence of second-period investments, together with the assumption that a firms' overall cash flows are ordered by first-order stochastic dominance, precludes any prediction about the issuance of equity in Goswami, Noe and Rebello (1995). In this case, both long term debt and equity represent claims on the firm's total cash flow, and thus equity is eliminated by the standard pecking order argument (Nachman and Noe, 1994).

Finally note that our results also compliment Korajczyk, Lucas, and McDonald (1992) where firms choose to issue equity when the extent of asymmetric information regarding firms' values is relatively low. In addition, we show that firms issue equity when the asymmetry regarding the timing of earnings is relatively high.

The rest of this paper is organized as follows. The next section presents a basic model description. Section 3 analyses the separating equilibria. Section 4 presents the model implications and compares the results with other theories. Section 5 suggests several extensions of the basic model and discusses the robustness of its results. The conclusion is drawn in Section 6 .

\footnotetext{
${ }^{5}$ Recall that in the present paper the investment is two-staged and asymmetric information exist about earnings from both stages of the investment.
} 


\section{Basic model.}

Consider a firm with a two-stage investment project. In each period, indexed by $t=1,2$, an amount $b$ has to be invested. In each period the project can either be successful or unsuccessful. There are two types of firms: for firm $i$ the probability of success in period $t$ equals $\theta_{i t}$ and for firm $s$ it is $\theta_{s t}$. The cash flow of type $x=i, s$ in period $t$ is denoted by $r_{x t}$. In the case of success $r_{x t}=1$, otherwise $r_{x t}=0$. Total expected cash flow for type $x$ over both periods is then $v_{x}=\theta_{x 1}+\theta_{x 2}$. We assume the $\theta$ 's are restricted to the interval $(b, 1]$, which implies that the investment has positive net present value in each period. Firm $i$ is "performance-improving" relative to firm $s$ ("stagnating") because

$$
g_{i} \geq g_{s}
$$

where $g_{x}$ denotes the rate of earnings growth $\left(\theta_{x 2} / \theta_{x 1}\right)$. A firm $x$ has increasing expected cash flows if $g_{x}>1$, and the cash flow profile is flat or declining if $g_{x}=1$ or $g_{x}<1$ respectively. The firm's performance can be described by a pair $\left(v_{x}, g_{x}\right)$. The probabilities of success in each stage are then:

$$
\theta_{x 1}=\frac{v_{x}}{1+g_{x}} \text { and } \theta_{x 2}=\frac{v_{x} g_{x}}{1+g_{x}}
$$

The extent of asymmetric information regarding long-term cash flows is greater than or equal to that of short-term cash flows:

$$
\left|\theta_{i 1}-\theta_{s 1}\right| \leq\left|\theta_{i 2}-\theta_{s 2}\right|
$$

Short-term performance may be significantly related to the firm's past activities which may be known to the public while long-term performance relies more heavily on new decisions.

The firm's profit is observable and verifiable. There exists universal riskneutrality and perfect competition among investors. This implies zero market profit and risk-neutral valuation for any security issued.

\subsection{Financing strategies}

In the first period the firm $x=i, s$ may issue equity (denote this strategy by $e$ ), short-term $(d)$ or long-term debt $(l) .^{6}$

Equity financing. In the first period the firm issues $\Delta n_{x}$ shares for the price $p$ such that the amount of financing covers the investment needs: $p \Delta n_{x}=b$ where $p$ denotes the market price of shares. After observing the first-period cash flow $r_{x 1}$ the firm may distribute dividends $D_{x 1}^{r_{x 1}}$ or may use funds $f_{x}^{r_{x 1}}$ to finance the second stage internally: $r_{x 1}=D_{x 1}^{r_{x 1}}+f_{x}^{r_{x 1}}{ }^{7}$ In the second period

\footnotetext{
${ }^{6}$ In Section 5, we consider a model extension with mixed financing as well as other extensions.

${ }^{7}$ Theoretically the firm can also keep cash until the second period. However, this scenario never appears in equilibrium and thus it is excluded for simplicity. We consider the scenario with dividend covenants where the firm must keep some cash later.
} 
firms do not finance with equity. ${ }^{8}$ Hence, in the second period, the firm has the choice between internal financing and debt (the amount of debt equals $b-f_{x}^{r_{x 1}}$ ). Denote the second-period debt face value by $F_{2}^{r_{x 1}}$. The second-period cash flow $r_{x 2}$ is distributed, in total, to the claimholders.

Short-term debt. The firm issues debt with face value $F_{1}$ which matures at $t=1$. If $r_{x 1}=0$ (default) then two situations are possible. If $V_{2} \geq F_{1}$ (where $V_{2}$ is the firm's going concern value expected by investors) then the firm will rollover the existing debt by issuing a new claim with a real value equal to $F_{1}$ (Diamond (1991), Goswami, Noe and Rebello (1995)). If $V_{2}<F_{1}$ then the creditors can get control over the firm. If control passes to the creditors, the second-period value of the firm is $V_{2}^{c}=\gamma V_{2}$, where $\gamma \in[0,1] . \gamma$ may have two interpretations. First, it may mean that there are bankruptcy or reorganization costs. An alternative interpretation is that the entrepreneur has a superior ability to run the firm and its replacement reduces the firm's value. To avoid a social loss when $\gamma<1$ the firm can continue operating under the control of the initial shareholders. This decision depends on the renegotiation between the entrepreneur and the creditors. The renegotiation is conducted in the following manner: the entrepreneur makes a "take-it-or-leave-it" offer to the creditors to exchange their existing claims for new claims with face value $F^{r}$ which mature in $t=2 .{ }^{9}$ The creditors may accept or reject the offer. If the offer is rejected the creditors get the firm's equity and the shareholders get nothing.

Long-term debt. Long-term debt has face value $F_{2}$ and matures in $t=2$. It can be senior or junior. If it is senior then any new claim issued in the second period will be subordinated and vice versa. When long-term debt is junior, the firm is always able to raise funds for financing the second stage when internal funds are insufficient. However, if the firm's expected cash flow in the second stage is low and debt is senior, the firm may be not able to raise funds to finance the second stage. This may create a debt overhang problem. Since this leads to inefficiency, the parties may renegotiate at the end of the first period. We continue to assume that shareholders make "take-or leave-it" offer to the creditors.

The firm's type is revealed to the entrepreneur in period 0 while financing and investments take place in periods 1 and 2. The firm's initial capital structure is $100 \%$ equity, with $n$ shares outstanding. Let $\alpha_{x t}$ denote the proportion of equity owned by the entrepreneur in period $t$ (immediately after the issue of securities in period $t$, if it takes place). Clearly, $\alpha_{x 0}=1$. The second-period financial outsiders observe the first-period capital structure choice and first-period cash flow. Throughout this article, we use the concept of Perfect-Bayesian equilibria.

For our purposes it will be suitable to present a set of exogenous parameters

${ }^{8}$ This is based on Myers and Majluf's (1984) result that in a one-stage investment setting equity is never issued under asymmetric information.

${ }^{9}$ Under an alternative scenario the parties may divide the surplus from continuation in the proportion 50-50 (Nash solution) or in other proportions. This will not change the model results as long as the value of the firm under the creditors control is related to the firm value under the shareholders control. See Giammarino (1989) for different defaults scenarios under asymmetric information. 
describing the model as $\left(v_{i}, g_{i}, v_{s}, g_{s}, b, \gamma\right)$. In the next section we will analyze the parameter values under which a separating equilibrium may exist.

\section{Separating equilibria.}

When the extent of asymmetric information regarding firms' total values is large, a separating equilibrium does not exist: the type with low value mimics that with high value. When the extent of asymmetric information regarding firms' total values is relatively small and that concerning the timing of earnings is relatively large, a separating equilibrium may exist. In this case, $i$ has lower performance in the first period and higher performance in the second period. In such an environment, prices can be affected by the "lemon" effect in both periods. Intuitively, $i$ has a "lemon" advantage in the first period: with lower profits in this period, $i$ can capitalize on the adverse selection problem. On the other hand, in the second period the "lemon" advantage passes to $s$. $i$ and $s$ face very different incentives regarding financial decisions. The point is that the price of first-period equity depends on the firms' total values and it does not on the timing of cash flows. As a result, if $i$ were to issue equity in the first period, it cannot benefit from its "lemon" advantage in the first period (given that the difference between firms' total values is low enough). Thus, $i$ would always be mimicked by $s$, who stands to gain in the second period by being perceived as growing and, therefore, as expecting high profits in the second period. The implication is that $i$ is at a disadvantage for issuing equity in the first period. To signal its type, $i$ can issue debt. In particular, if the cost of bankruptcy is high enough, first-period interest rates will be relatively high compared to those of the second period (since $i$ is considered "bad" in the first period and "good" in the second). Given such an interest rate profile, we show that if $s$ plays debt, it will be beneficial to creditors, but not to the firm. This is because creditors benefit from the high interest rates in the first period and the fact that $s$ does well in that period. In what follows we develop these ideas.

Let $V_{k m}^{j} \equiv V^{j}\left(v_{k}, g_{k}, v_{m}, g_{m}, b, \gamma\right)$ be the expected payoff to the entrepreneur of type $k$ (with total value $v_{k}$ and rate of growth $g_{k}$ ) if the strategy $j, j \in\{e, d, l\}$ is played and the type is perceived by the market as type $m$ (with the parameters $v_{m}$ and $\left.g_{m}\right), k, m \in\{i, s\}$. A separating equilibrium is a situation where type $i$ plays strategy $j_{1}$, type $s$ plays strategy $j_{2}$ and no type has an incentive to mimic the other type:

$$
V_{i s}^{j_{2}} \leq V_{i i}^{j_{1}} \text { and } V_{s i}^{j_{1}} \leq V_{s s}^{j_{2}}
$$

It is thus clear that the analysis of the $V_{k m}^{j}$ function is crucial. The value of $V_{k m}^{j}$ depends on the performance of type $k$ and the prices of issued securities. The latter are equal to the symmetric information prices for type $m$ which will be marked with subscript $m$, for instance the symmetric information share price for type $m$ is $p_{m}$ and the face value of short-term debt is $F_{m 1}$. We have:

$$
V_{k m}^{e}=\alpha_{k 1} E_{r_{k 1}}\left[D_{k 1}^{r_{k 1}}+E_{r_{k 2}} D_{k 2}^{r_{k 1} r_{k 2}}\right]
$$


where $\alpha_{k 1}=\frac{n}{n+\Delta n_{k}}=\frac{n}{n+b / p_{m}}$ denotes the fraction of equity retained by the entrepreneur after issuing shares and $E_{r_{k 1}}\left[D_{k 1}^{r_{k 1}}+E_{r_{k 2}} D_{k 2}^{r_{k 1} r_{k 2}}\right]$ denotes the expected dividends in periods 1 and 2 .

$$
\begin{gathered}
E_{r_{k 1}} D_{k 1}^{r_{k 1}}=\theta_{k 1}\left(1-f_{k}^{1}\right) \\
E_{r_{k 1} r_{k 2}} D_{k 2}^{r_{k 1} r_{k 2}}=\theta_{k 1} \theta_{k 2}\left(1-F_{m 2}^{1}\right)+\left(1-\theta_{k 1}\right) \theta_{k 2}\left(1-F_{m 2}^{0}\right)
\end{gathered}
$$

Given $i$ performs better than $s$ in the second period, $i$ will always use internal financing in the second period if available in order to avoid the lemon problem. In contrast, $s$ pays out as much cash in dividends as possible and uses external financing. This is quite intuitive and thus formal proof is omitted for brevity. Finally, we have

$$
V_{k m}^{e}=\alpha_{k 1}\left[\theta_{k 1}\left(1-f_{k}^{1}+\theta_{k 2}\left(1-F_{m 2}^{1}\right)\right)+\left(1-\theta_{k 1}\right) \theta_{k 2}\left(1-F_{m 2}^{0}\right)\right]
$$

Let us turn to strategy $d$. Consider $r_{k 1}=0$. If $V_{2} \geq F_{m 1}$, where $V_{2}=\theta_{m 2}-b$, the firm will issue a new claim which matures in $t=2$ with the face value equal to $F_{m}^{r}$ and with the real value equal to $F_{m 1}: F_{m}^{r}=F_{m 1} / \theta_{m 2}$. This claim will be sold for $F_{m 1}$ (recall that the creditors perceive the firm as type $m$ ) and the proceeds from this issue will be used to pay off the existing debt. If $\theta_{m 2}-b<F_{m 1}$ then the shareholders will offer the creditors a fraction $\gamma$ of the firm's equity (it can be a new debt claim). This offer will be accepted because it provides the highest value (in case the firm is $m$ the value of equity offered to the creditors equals $\left.\gamma\left(\theta_{m 2}-b\right)\right)$ the creditors can get through bankruptcy and getting control over the firm (according to their equilibrium beliefs about the firm's type). If the fraction of equity offered to the creditors is less than $\gamma$ the creditors will reject the offer. In this case the shareholders get nothing and thus they have no interest to do so. To summarize, we get the following. If $\theta_{m 2}-b<F_{m 1}$ then

$$
V_{k m}^{d}=\theta_{k 1}\left(1-F_{m 1}-f_{k}^{1}+\theta_{k 2}\left(1-F_{m 2}^{1}\right)\right)+(1-\gamma)\left(1-\theta_{k 1}\right) \theta_{k 2}\left(1-F_{m 2}^{0}\right)
$$

and otherwise

$$
V_{k m}^{d}=\theta_{k 1}\left(1-F_{m 1}-f_{k}^{1}+\theta_{k 2}\left(1-F_{m 2}^{1}\right)\right)+\left(1-\theta_{k 1}\right) \theta_{k 2}\left(1-F_{m}^{r}-F_{m 2}^{0}\right)
$$

where $F_{m}^{r}=F_{m 1} / \theta_{m 2}$.

Similarly for strategy $l$ we get the following. If $1 \geq F_{m 2}+F_{m 2}^{0}$

$$
V_{k m}^{l}=\theta_{k 1}\left(1-f_{k}^{1}+\theta_{k 2}\left(1-F_{m 2}-F_{m 2}^{1}\right)\right)+\left(1-\theta_{k 1}\right) \theta_{k 2}\left(1-F_{m 2}-F_{m 2}^{0}\right)
$$

The case $1<F_{m 2}+F_{m 2}^{0}$ never appears in equilibrium as shown in the Appendix (proof of Lemma 1).

The following lemma determines the prices of issued securities under symmetric information that that are necessary for the analysis of the $V_{k m}^{j}$ function.

Lemma 1. If information is symmetric then for type $x=i, s$ :

$$
p_{x}=\left(\theta_{x 1}+\theta_{x 2}-2 b\right) / n=\left(v_{x}-2 b\right) / n
$$




$$
\begin{gathered}
F_{x 1}=\left\{\begin{array}{c}
\frac{b-\gamma\left(1-\theta_{x 1}\right)\left(\theta_{x 2}-b\right)}{\theta_{x 1}}, \theta_{x 2}<2 b \\
b, \theta_{x 2} \geq 2 b
\end{array}\right. \\
F_{x 2}^{r_{x 1}}=\left(b-f_{x}^{r_{x 1}}\right) / \theta_{x 2} \\
F_{x}^{r}=b / \theta_{x 2}
\end{gathered}
$$

Financing with long-term debt is only possible if $\theta_{x 2} \geq 2 b$ and

$$
F_{x 2}=b / \theta_{x 2}
$$

(Proofs of all lemmas and propositions are collected in the Appendix)

As one can see from Lemma 1 the values of different securities depend in different ways on the firm's expected performance in each period. Since each type performs differently in each period the value of securities issued by different types are different. To avoid mimicking, firms will issue securities which have a lower value compared to the other type. In this sense the following remarks about Lemma 1 are useful. Equation (9) implies that $p_{x}$ depends only on the firm's total profit and not on its profit profile over time. Total expected cash flow equals $\theta_{x 1}+\theta_{x 2}$. Total investment is $2 b$. Total expected earnings are thus $\theta_{x 1}+\theta_{x 2}-2 b$ which implies $(9)$.

If $\theta_{x 2}$ is sufficiently high $\left(\theta_{x 2} \geq 2 b\right)$ then short-term debt is risk-free because the firm can rollover this debt if $r_{x 1}=0$ (a similar situation occurs in, for instance, Flannery, 1986). If $\theta_{x 2}<2 b$ then as follows from (10), the short-term debt face value is positively linked to the amount of borrowing and negatively related to both the expected performance in the first- and second-periods and to the reorganization costs.

For long-term debt, if $\theta_{x 2} \geq 2 b$ the value of debt depends only on the expected second-period performance. The firm cannot default in the first period (it does not matter whether the debt is senior or not) and all first-period earnings will be distributed to the shareholders. This is because internal financing in the second period increases the value of the creditors claim and reduces the shareholders value. Now when $\theta_{x 2}<2 b$ financing with long-term debt is impossible regardless of whether long-term is senior or not (although the explanations are different in both of these cases).$^{10}$

From (11) the second-period debt face value is positively linked to the amount of external financing in the second period and negatively related to both expected second-period performance and retained earnings.

\footnotetext{
${ }^{10}$ If debt is subordinated then the firm will also distribute all dividends to the shareholders and finance the second stage by borrowing. External investors will agree to provide secondperiod financing because their claim will be senior. When $\theta_{x 2}<2 b$ the expected payoff to the long-term creditors is less than $b$. If long-term debt is senior and $\theta_{x 2}<2 b$ then in the end of the first period the firm will face the debt overhang problem- it will not be able to raise funds for the second stage. To avoid a debt overhang problem the parties will renegotiate. The maximum payoff the long-term creditors can get in the second period equals the firm's going concern value. Again when $\theta_{x 2}<2 b$ the firm's going concern value $\left(\theta_{x 2}-2 b\right)$ is less than $b$ which in turn implies that the expected payoff to the long-term creditors cannot cover the investment cost.
} 
It follows from Lemma 1 and the definition of $V_{k m}^{j}$ that $V_{k k}^{j}=\theta_{k 1}+\theta_{k 2}-$ $2 b$ for any $j \in\{e, d, l\}$. The right side shows the expected payoff of type $k$ under symmetric information: it equals total expected cash flow minus the costs of investment which is not surprising in this Modigliani-Miller environment. This can be proven by substituting the prices of securities under symmetric information into the expressions for $V_{k m}^{j}$.

Lemma 1 has several implications for the existence of separating equilibrium. For instance, if $\theta_{i 1} \geq \theta_{s 1}$ or $\theta_{s 2} \geq \theta_{i 2}$ then one type has better performance than the other in both periods and thus by Lemma 1 any claim issued by this type has higher value.

Lemma 2. If $\theta_{i 1} \geq \theta_{s 1}$ or $\theta_{s 2} \geq \theta_{i 2}$ a separating equilibrium does not exist.

Corollary 1. If $g_{i}=g_{s}$ a separating equilibrium does not exist.

It follows from Lemma 2 and Corollary 1 that if the firms' rates of profit growth are equal or if one type has higher performance in both periods than the other, a separating equilibrium does not exist: the type with higher value will always be mimicked. We thus consider the case where the type with higher rate of earnings growth has lower performance in the first stage and higher performance in the second stage than the stagnating type:

$$
\begin{gathered}
\theta_{i 1}<\theta_{s 1} \quad \theta_{s 2}<\theta_{i 2} \\
g_{i}>g_{s} \\
v_{i} \geq v_{s}
\end{gathered}
$$

The latter follows from (3) and (14).

From (14) firms with high rate of earnings growth have low performance in the first period and high performance in the second period relative to "stagnating" firms. Intuitively, firms with a high rate of earnings growth appear to have a "lemon" advantage in the first period: lower profits in this period mean that this type of firm can capitalize on the adverse selection problem. On the other hand, in the second period the "lemon" advantage passes to firms with a low rate of earnings growth.

For our purposes the following definition will be useful. Let $R_{k m}^{j}$ be the expected surplus (the difference between the expected equilibrium payoff and the symmetric information payoff) to the entrepreneur of type $k$ if the strategy $j$ is played and the type is perceived by the market as the type $m . R_{k m}^{j}=$ $V_{k m}^{j}-\theta_{k 1}-\theta_{k 2}+2 b$. Obviously $R_{k k}^{j}=0$ which corresponds to the symmetric information case. From (4) a separating equilibrium exist if

$$
R_{i s}^{j_{2}} \leq 0 \text { and } R_{s i}^{j_{1}} \leq 0
$$

Lemma 3. $\partial R_{k m}^{j} / \partial v_{m}>0$ for any $j \in\{e, d, l\}$.

On the intuitive level Lemma 3 is straightforward: under asymmetric information a firm's expected surplus increases if the market value of the firm 
(the value of the firm from the investor's viewpoint) increases. A more intriguing question is how changes in a firm's earnings growth rate affect $R_{k m}^{j}$. This question is at the core of the analysis below.

From (2) an increase in the rate of earnings growth increases the firm's expected performance in the second period. We know, from Lemma 1, that the price of equity depends on the value of the firm, and not just first-period performance. The value of any claim issued by the firm in the second period depends heavily on the firm's second-period expected performance. Hence an increase in the market's perception of the firm's rate of earnings growth increases the expected payoff of the firm issuing equity.

Lemma 4. $\partial R_{k m}^{e} / \partial g_{m}>0$.

Proposition 1. A separating equilibrium where $i$ issues equity does not exist.

Proposition 1 is based on Lemmas 3 and 4, and on (15) and (16). An explanation for this result is as follows. Since the price of equity depends on the value of the firm, and not just first-period performance, $i$ cannot benefit from its "lemon" advantage in the first period. Moreover, $i$ will lose in the second period because of $s$ 's "lemon" advantage in this period. While when $r_{i 1}=1$, $i$ can use internal financing to mitigate the adverse selection problem linked to external financing in the second period, this problem is inevitable if $r_{i 1}=0$. This logic also underlines the existence of a separating equilibrium, where $i$ uses debt financing and $s$ uses equity financing.

Consider a separating equilibrium where $s$ plays equity and $i$ plays shortterm debt. This equilibrium exists if and only if the following holds:

$$
\begin{aligned}
& R_{s i}^{d} \leq 0 \\
& R_{i s}^{e} \leq 0
\end{aligned}
$$

The first condition is the non-deviation condition for $s$. The second condition is the non-deviation condition for $i$. Applying the above reasoning one can show that $i$ will not mimic $s$ when the latter issues equity and (19) holds. Now consider (18). This only holds under some values of the parameters and does not hold otherwise. If the second-period expected performance of type $i$ is high enough to cover the cost of investment over both periods $\left(\theta_{i 2} \geq 2 b\right)$ a separating equilibrium does not exist: $s$ mimics $i$ because $s$ benefits from the low face value of debt in the second period while first-period debt is risk-free by Lemma 1 and it does not imply any value loss for $s$. We thus continue with the case $\theta_{i 2}<2 b$. Generally speaking, for $i$ to separate from $s, i$ must issue claims with a value which depends heavily on first-period expected performance when $i$ is weak. Recall that the set of model parameters is $\left(v_{i}, g_{i}, v_{s}, g_{s}, b, \gamma\right)$. We will show that there exists a clear role for every parameter in balancing the weights of first-period and second-period expected performances in the value of debt.

Lemma 5. $\partial R_{s i}^{d} / \partial \gamma>0$.

The intuition behind Lemma 5 is as follows. If $\gamma$ is low then first-period creditors will not significantly rely on the firm's second period performance. Low $\gamma$ implies high reorganization costs or that it is costly to transfer ownership 
from the shareholders to creditors if the firm defaults in the first period. Thus the firm's first-period expected performance becomes crucial in valuing debt. Since $i$ has low first-period expected performance, mimicking $i$ is not profitable for $s$ and vice versa. Lemma 5 leads to the following proposition.

Corollary 2. Either $R_{s i}^{d}>0$ for any $\gamma$ or there exists $\gamma^{*} \in[0,1]$ such that $R_{s i}^{d} \leq 0$ if and only if $\gamma \leq \gamma^{*}$ (other parameters being equal). ${ }^{11}$

Proposition 2. A separating equilibrium where $i$ issues short-term debt and $s$ issues equity exists if and only if $\gamma^{*}$ exists (Corollary 2) and $\gamma \leq \gamma^{*}$.

Now consider how changes in $v$ 's and $g$ 's affect the existence of equilibrium. Two ideas underline the analysis below. First when the difference between firms' total values is large enough a separating equilibrium does not exist because the type with a low total value will mimic the high value type. On the other hand, a large difference in the firms' rates of earnings growth contributes to the existence of equilibrium by making it possible for $i$ to design debt claims which will not be mimicked by $s$.

Lemma 6. 1) Either $R_{s i}^{d}>0$ for any $g_{s}$ (other parameters being equal) or there exists $g_{s}^{*}$ such that $R_{s i}^{d} \leq 0$ if and only if $g_{s} \leq g_{s}^{*}$; 2) $\partial R_{s i}^{d} / \partial v_{s}<0$ and either $R_{s i}^{d}>0$ for any $v_{s}$ (other parameters being equal) or there exists $v_{s}^{*}$ such that $R_{s i}^{d} \leq 0$ if and only if $v_{s} \geq v_{s}^{*}$.

Proposition 3. A separating equilibrium where $i$ issues short-term debt and $s$ issues equity exists if and only if the following holds: 1) $g_{s}^{*}$ exists (Lemma 6) and $g_{s} \leq g_{s}^{*}$; 2) $v_{s}^{*}$ exists (Lemma 6) and $v_{s} \geq v_{s}^{*}$.

Proposition 3 follows directly from Lemma 6 and our previous discussion of this equilibrium (equations (18) and (19)). Similarly we have the following results. A separating equilibrium where $i$ issues short-term debt and $s$ issues equity exists if $g_{i}$ is sufficiently high (other parameters being equal) and $v_{i}$ is sufficiently low (close to $v_{s}$ ).

Figure 1 illustrates Proposition 3. Here $g_{i}=1.5, v_{i}=1.6, \theta_{i 1}=0.64, \theta_{i 2}=$ $0.96, b=0.6$ and $\gamma=0.4$. The figure shows under which values of $g_{s}$ and $v_{s}$ separating equilibriums may exist. In the space below the thick line $(A)$ the separating equilibrium, where $i$ plays debt and $s$ plays equity, exists. In $B$ the separating equilibrium does not exist. Note that for any value of $v_{s}$ a separating equilibrium exists if $g_{s}$ is low enough and for any $g_{s}$ a separating equilibrium exists if $v_{s}$ is high enough. In other words a separating equilibrium exists if asymmetric information about rate of earnings growth is more important than that concerning the firms' total values. Also note that a separating equilibrium does not exist when $g_{s}=g_{i}=1.5$ for any value of $v_{s}$ as was discussed in Section 3.1 .

\footnotetext{
${ }^{11}$ Long mathematical expressions showing the cutoff value $\gamma^{*}$ are omitted for brevity. Also note that the corner solution condition when $R_{s i}^{d}>0$ for any value of $\gamma$ is given by substituting $\gamma=0$ in (18) which is: $\theta_{s 1} / \theta_{i 1}+\theta_{s 2} / \theta_{i 2} \leq 2$. Its analysis is also omitted for brevity as well as some corner conditions for following propositions because they do not add a lot of new intuitions besides those described in the text.
} 


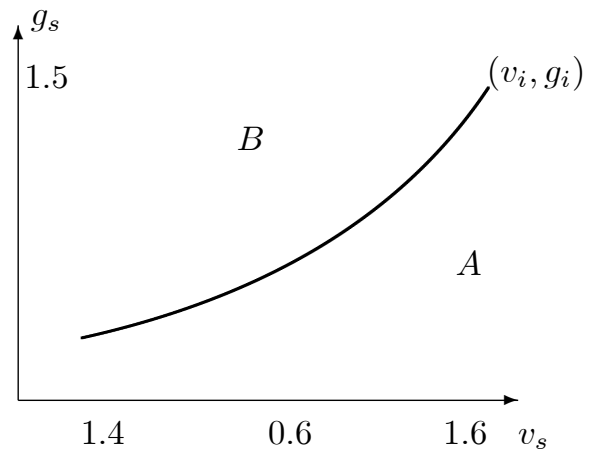

Figure 1. Separating equilibria with short-term debt and equity.

Finally we have the following result.

Proposition 4. A separating equilibrium where $i$ issues long-term debt does not exist.

By Lemma 1, the value of long-term debt corresponding to type $i$ is lower than that of type $s$ and therefore if this type issues long-term debt it will be mimicked by $s$.

\section{Implications.}

The analysis of this paper implies that when private information is two-dimensional and contains information about firm value and the cash flow profile over time, the choice between debt and equity may be used as a signaling device. A separating equilibrium may exist where type $i$ issues debt and type $s$ issues equity. This equilibrium has the following predictions:

(i) Firms issuing equity have lower operating performance in the long run as compared to non-issuing firms $\left(\theta_{s 2}<\theta_{i 2}\right)$. This conclusion is confirmed by empirical findings for IPO firms (see, among others, Jain and Kini (1994), Pagano, Panetta and Zingales (1998), Cai and Wei (1997), Mikkelson et al. (1997) and Purnanandam and Swaminathian (2004)) and for SEO (seasoned equity issues) firms (Loughran and Ritter, 1997). ${ }^{12}$ (ii) These firms have a lower ratio of long-term earnings to short-term earnings as compared to nonissuing firms $\left(g_{s}<g_{i}\right)$. (iii) The absolute performance of firms issuing equity exceeds the performance of non-issuing firms at the time of issue or in the near future after issue $\left(\theta_{s 1}>\theta_{i 1}\right) \cdot{ }^{13}$

Existing literature suggests few explanations for the long-term underperformance of firms issuing equity. Among basic rational market intuitions, the

\footnotetext{
${ }^{12}$ Note that in the context of our model, the non-equity-issuing firms are actually the ones who issue debt. As Eckbo, Masulis and Norli (2000) mention, and Eckbo and Norli (2001) empirically confirm, issuing firms have lower leverage relative to non-issuing firms. This is consistent with the idea that, unlike issuing firms, non-issuing firms prefer debt financing.

${ }^{13}$ The empirical evidence on this point was discussed in the introduction.
} 
following theories are notable. The theory of agency cost of equity (Jensen and Meckling, 1976) underlines the idea that equity issues decrease the manager's stake in the company and reduce the incentive to undertake value maximizing projects. This results in afterissuing underperformance of the firm, though the theory does not compare the performance in the short run with that in the long run after the issue. Also note that the link between afterissuing underperformance and a low managerial fraction of equity is empirically controversial. For instance, Pagano et al. (1998), Cai and Loughran (1998) and Mickelson et al. (1997) do not confirm the positive correlation between the fraction of insiders' equity and firm performance.

The trade-off theory in its standard form, proposing that firms equalize the marginal tax benefits associated with additional debt to the marginal cost of bankruptcy, suggests that more profitable firms should issue more debt. However, it will not predict the link between debt-equity choice and dynamic profile of performance after the issue (long-term performance versus short-term performance). For instance, it will predict that type $s$ (high expected performance in the first period) should issue more debt than $i$ in the first period in contrast to our results. According to the free cash flow theory (Jensen, 1986) debt is an instrument for solving the problem of a manager's entrenchment and thus more debt should lead to higher overall performance. However, this theory does not give an explanation for why firms should issue equity. This theory would also suggest that type $s$ (with high expected performance in the first period) should issue debt in order to prevent managers from overspending. Recently several dynamic versions of the trade-off model were developed which combine taxes, bankruptcy costs and different kinds of agency costs. Typically, these models lead to less extreme and more realistic predictions than the basic ideas do. However, we have not found a model which systematically analyzes the link between debt-equity choice and dynamic profile of operating performance after the issue. We will provide more discussion of dynamic trade-off models later when we discuss the correlation between debt and profitability.

The market timing argument (see, for instance, Baker and Wurgler, 2002) points out that while in Modigliani and Miller environment the capital structure decisions are not affected by the magnitude of share prices or by the "hotness" of the market, in reality one observes that firms tend to issue equity when the market prices are relatively high and do not issue equity when the prices are relatively low. To relate this observation to the evidence about operating performances, one line of the literature focuses on non-rational aspects of investors behavior. For instance, some research argues that investors tend to be overoptimistic during new issues or that the analysts' forecasts are inadequately high. ${ }^{14}$ The firms thus sell shares when they are overvalued or the firm is expected to perform poorly compared to the price of the issue. Theo, Welch and Wong (1998) argue that managers manipulate earnings (sacrifice future earnings by pushing up current earnings) prior to going public in order to attract more non-informed investors. We share with this paper the idea that managers may

${ }^{14}$ For references see Ritter and Welch (2002) or Loughran and Ritter (1997). 
be involved in earnings management leading to their private information about the timing of cash flows. However our framework assumes completely rational investors which infer information about a firm's earnings profile from observing its financing decision. ${ }^{15}$ The difference between these two approaches (rational market versus non-rational) is not only theoretical. Some recent empirical research argues in favor of efficient market version of the market timing argument (Schultz (2003) and Butler, Grullon and Weston (2005)) - "pseudo-market timing" - where shares are not overpriced.

When investors are rational the prices are supposed to correctly reflect firms' current and future earnings and not only current earnings. In such an environment and assuming that there is no asymmetric information or agency costs, how can one explain that first, firms time their issues and second, why the firms issue shares when operating performance is high and why it becomes low in the long run after issue? The literature based on rational investors is able to argue why firms may be interested in issuing equity in periods when market prices are high although it is not focused on explaining the link between debt-equity choice and changes in operating performance after issue (long-term versus short-term). ${ }^{16}$

Below we show that the separating equilibrium described in this paper is consistent with market timing (or rather "pseudo-market timing") empirical evidence. In period 0 before the information about the firm type is acquired by managers and before the financing decision is made the market share price equals $p_{0}=\mu\left(v_{i}-2 b\right) / n+(1-\mu)\left(v_{s}-2 b\right) / n$, where $\mu$ denotes the proportion of firms of type $i$. After the managers of type $s$ get information about earnings they will realize that the true value of type $s$ shares is $\left(v_{s}-2 b\right) / n$. Since the market price will still remain the same because the investors do not know the firm's type the managers of type $s$ will see their shares to be overvalued if $\mu>0$ : $p_{0}>\left(v_{s}-2 b\right) / n$ which follows from (16). They then issue equity. Investors will infer correctly that equity is issued by type $s$. The price fall during the issue of shares reflects the well-known underpricing of newly issued shares phenomenon. Also the second-period share price of type $S\left(p_{s 2}\right)$ is lower than its first-period price.

Proposition 5. In a separating equilibrium where $i$ issues debt and $s$ issues equity $p_{0}>p_{s}>p_{s 2}$.

Note that the investors remain completely rational in our model and have zero-profit in equilibrium.

Both the agency and trade-off theory also provide insight into market timing. According to the debt overhang problem (Myers, 1977) an excessive senior debt

\footnotetext{
${ }^{15}$ Stein's (1989) model explains earnings inflation in a rational world but it does not explicitly analyzes a debt-equity choice problem.

${ }^{16}$ In addition to previously mentioned Lucas and McDonald (1990) note that in Berkovitch and Narayanan (1993) firms can time their projects and the financial market is imperfect (there are switching rents imposed by intermediaries). Low-profit projects tend to be financed with equity and high-profit projects with debt. Firms will develop only the projects with sufficiently high quality. In recession, only highly profitable projects will be undertaken (with debt financing) and low-profit projects will be shelved until an expansion occurs. This paper offers an explanation for why more equity is issued during expansions.
} 
may lead the firm to forego some valuable investment opportunities. Thus, a firm with high market value of shares and good investment opportunities respectively will lose more from underinvestment and will thus issue equity instead. However it is not straightforward to predict a link between equity issues and subsequent operating performance consistent with observable evidence without making additional assumptions about, for instance, the link between share price and current operating performance. ${ }^{17}$ An advantage of the present paper compared to Myers (1977) (and some other theories mentioned in this section) is that it is not based on the link between profitability and investment opportunities (for instance Jain and Kini (1994) and Loughran and Ritter (1997) do not find that afterissuing underperformance is due to the lower or higher amounts of investment). In our model, all firms invest the same amount of funds and the difference comes only from future operating performance profiles. Finally note that Baker and Wrugler (2002) do not find a lot of support for underinvestment theory of market timing.

(iv) The model predicts that leverage is negatively correlated with profitability. ${ }^{18}$ To see this let us look at the dynamics of capital structure (in market values) of both types of firms over two periods. Consider the basic model and a separating equilibria where $i$ issues short-term debt and $s$ issues equity. In period 1 (after the securities are issued until the earnings are received) the debt/equity ratio of type $s$ is 0 and that of type $i$ is $b /\left(v_{i}-2 b\right)$ (the denominator shows the market value of firm's equity). It is clear that the debt/equity ratio of type $i$ is higher than that of type $s$ while the opposite is true for average earnings in the first period. This conclusion does not change if one measures debt/equity ratios at the end of first period (after the earnings are received but before second-period financing decision is made). In the second period (after the second-period financing decision is made and before the second-period earnings are received) the debt/equity ratio of type $s$ is $b /\left(\theta_{s 2}-b\right)$ and that of type $i$ is $b /\left(\theta_{i 2}-b\right)$. We see that the debt/equity ratio of type $s$ is higher because $\theta_{s 2}<\theta_{i 2}$ which confirms the negative correlation between debt and profitability in the second period as well.

Note that the trade-off theory in its standard form is inconsistent with the negative correlation between debt and profitability because highly-profitable firms should tend to finance with debt in order to reduce their taxes. Hennessy and Whited (2005) develop a dynamic trade-off theory with the idea that a profitable firm does not have to distribute its earnings immediately as the standard models assume. This may reduce the incentive to reduce taxes by issuing debt. The financing decision depends on the next period financing margin or what the firm is going to do in the future: to issue more equity, to distribute more earnings or to remain neutral. While providing a valid intuition about why the static trade-off may not work, the authors do not obtain a theoretical propo-

\footnotetext{
${ }^{17}$ If one assumes that high current performance corresponds to the high share price then it can explain point (ii). It will still be difficult to explain why a firm issuing equity should underperform in the long run after issuing equity and undertaking all its investment opportunities.

${ }^{18}$ See, for instance, Titman and Wessels (1988) and Rajan and Zingales (1995).
} 
sition about the link between debt and profitability. However, they do show numerically that under some plausible values of parameters one can observe the negative correlation between debt and profitability in their model.

Zwiebel (1996) develops a dynamic model of capital structure based on the managers' entrenchment argument. The paper suggests that when a firm has more valuable investment opportunities the need to issue new debt as a disciplinary device decreases which leads to the situation where firms with lower debt are likely to be more profitable. While providing an idea about the negative correlation between debt and profitability the paper does not explain why firms issuing equity underperform in the long run. Also equity financing is not explicitly analyzed in the model.

Several empirical predictions which have not been tested in the literature follow from Propositions 2 and 3. (v) Long-term operating underperformance of firms issuing equity should more frequently be observed when reorganization costs increase (Proposition 2); (vi) this phenomenon should more frequently be observed when asymmetric information regarding the timing of cash flows is larger than that regarding the total cash flows (Proposition 3). Possible tests of these predictions will be based on identifying firms and industries with high and low reorganization costs (bankruptcy cost). For industries with high reorganization costs the underperformance of firms issuing equity should be a more frequent phenomenon. One can also use the spread in analysts' valuations of firms' shares as a proxy for the extent of asymmetric information regarding the firms' total values and the spread in the forecasts of future earnings (longterm spread versus short-term spread) as a proxy for asymmetric information about future rates of earnings growth. Also firms manipulating earnings prior to issue (as in Theo and all, 1998) can be seen as ones with high degree of asymmetric information about timing of earnings since earnings management can often be seen as a redistribution of earnings between periods rather than accounting fraud (Degeorge, Patel and Zeckhauser, 1999).

Finally the model sheds some new light on possible motives for firms to use such financial instruments as dividend covenants, asset-backed securities and non-recourse debt which we discuss in the next section.

\section{The model extensions.}

5.1. Long-term debt with dividend covenants. Long-term debt can be issued with dividend covenants. The latter can establish maximal amount $(Y)$ of dividends the firm is allowed to pay in the first period. Intuitively a low $Y$ makes payments to creditors depend more heavily on the first-period cash flow. This allows type $i$ to explore its informational advantage related to their low first-period performance. One can show that a separating equilibrium may exist where $i$ issues long-term debt with dividend covenants and $s$ issues equity. The existence of this equilibrium is negatively related to the extent of asymmetric information regarding the firms' values and positively related to the extent of asymmetric information regarding the rates of earnings growth confirming the findings in 
basic model.

5.2. Mixed financing. In this subsection we allow the firm to issue any mix of different securities for financing. Allowing mixed financing provides little usefulness for the analysis of operating performance of firms issuing equity versus that of non-issuing firms. The reason is that most empirical literature on this topic does not differentiate issuers according to fractions of equity in capital structure. Even a marginally small issue of shares puts a firm into the category of issuing firms. Thus it will be hard to interpret the equilibrium in terms of existing empirical evidence. However, allowing for mixed financing is important with regard to the conclusions about the negative correlation between debt and profitability and more interestingly about the conditions of existence of this phenomena which constitute an addition to the literature on this phenomena.

Let

$$
b=b_{e}+b_{d}
$$

where $b_{e}$ and $b_{d}$ denote equity and debt (for simplicity of exposition we assume that debt is short-term). ${ }^{19}$ Hence the first-period financing policy can be described by, for instance, a variable $b_{e}, 0 \leq b_{e} \leq b$. Note that $b_{e}=0$ corresponds to pure short-term debt financing and $b_{e}=b$ corresponds to pure equity financing. Denote the entrepreneur's expected payoff if the type is $k$, strategy $b_{e}$ is played and the type is perceived by the market as $m$ by $V_{k m}\left(b_{e}\right)$.

The scenario when $b_{d}>0$ and $r_{x 1}=0$ is analogous to pure short-term debt financing. If $V_{2} \geq F_{1}$ the shareholders will offer the creditors a new claim with the real value equal $F_{1}$. This offer will be accepted because it is the best claim the creditors can get if they appeal. If the real value of new claim is less than $F_{1}$ the court will force an increase in the value of the new claim. If $V_{2}<F_{1}$ then the shareholders will offer the creditors a fraction $\gamma$ of the firm's equity. This offer will be accepted because it is the best value the creditors can get through bankruptcy and getting the control over the firm.

With mixed financing, firms have a much greater degree of freedom than in the basic model and thus the set of possible equilibriums becomes much larger. More precisely each combination of initial parameters $\varphi=\left(v_{i}, g_{i}, v_{s}, g_{s}, b, \gamma\right)$ can support several separating equilibrium, in most cases a continuum of equilibria. We will denote an equilibrium as $\sigma, \sigma \in \Xi(\varphi)$ where $\Xi(\varphi)$ denotes the set of all possible separating equilibriums when the exogenous parameters are given by $\varphi$. We will show however that in qualitative aspects the results are very similar to those found in the basic model. First of all, Lemma 7 (see Appendix) shows that the valuation of securities in this setting has a lot in common with pure financing scenarios. For instance, the share price depends only on the firm's total value and not on the rate of earnings growth. Secondly, we show that an increase of debt in the capital structure of type $i$ reduces the potential earnings of $s$ if it mimics $i$ and conversely an increase of equity in the capital structure of $s$ reduces the potential payoff of $i$ if it mimics $s$.

Lemma 8. $\partial V_{s i}\left(b_{e}\right) / \partial b_{e}>0 ; \partial V_{i s}\left(b_{e}\right) / \partial b_{e}<0$.

Lemma 8 leads to the following result.

\footnotetext{
${ }^{19}$ This assumption is not crucial.
} 
Proposition 5. For each set of exogenous parameters $\varphi$ there exist two subsets of separating equilibriums $\Xi_{1}$ and $\Xi_{2}, \Xi_{1} \cap \Xi_{2}=\varnothing, \Xi_{1} \cup \Xi_{2}=\Xi(\varphi)$ such that: 1) in any $\sigma \in \Xi_{1} \quad i$ uses a higher fraction of debt financing than $s$; 2) an equilibrium $\sigma$ where $i$ plays $b_{e}$ and $s$ plays $b_{e}^{\prime}$ belongs to $\Xi_{2}$ if and only if $\sigma^{\prime} \in \Xi_{2}$ where $\sigma^{\prime}$ is a separating equilibrium where $i$ plays $b_{e}^{\prime}$ and $s$ plays $b_{e} \cdot{ }^{20}$

$\Xi_{1}$ provides strong support for the results of the basic model about the negative correlation between debt and profitability. Firms issuing more equity (type $s$ ) have lower leverage during the first period and higher profitability in that period and vice versa in the second period. On the other hand, $\Xi_{2}$ is irrelevant in predicting the link between debt and profitability since on average among all equilibriums in this set, type $i$ has the same debt as type $s$. Thus, it is similar to a pooling equilibrium situation which is not able to generate any predictions of this kind.

Proposition 6. $\Xi_{1}$ is non-empty if and only if the conditions of propositions 2 and 3 hold.

Proposition 7 shows that the negative correlation between debt and profitability is likely to exist when asymmetric information regarding the timing of earnings is large and that about the firms' total values is small.

5.3. Up-front financing. If the firm is allowed to use up-front financing, the main results are not affected. Suppose that in the first period the firm issues securities with a total value larger than $b$, then invests $b$ in the first stage and keeps the rest for the second stage. Consider strategy $e$. One can show that the share price still depends only on the firm's total value. Thus the same logic applies. If $i$ uses up-front equity financing in equilibrium then the second period claims of type $i$ will be overpriced if type $s$ mimics type $i$ in equilibrium. Another problem with up-front financing is that keeping cash can be costly for the firm (Jensen, 1986). ${ }^{21}$

5.4. The case where short-term asymmetry is large and long-term asymmetry is small. Here we discuss the case when condition (3) does not hold. In this case a separating equilibrium may exist with $s$ issuing debt and $i$ issuing equity. The reason is that $i$ has a smaller total value than $s$ and if this difference is large enough a separation may exist. We can show that if such an equilibrium exists then there also exists an equilibrium where $i$ issues debt and $s$ issues equity. Thus, debt issues by $i$ will prevail (this is similar to subsection 5.2).

\section{Conclusions}

This paper examines optimal financing in a dynamic setting (two-stage investment process) under asymmetric information. The analysis is based on the idea that firms have private information about their earnings profiles over time.

\footnotetext{
${ }^{20}$ Similar approach was used in Goswami, Noe and Rebello (1995), proposition 3.

${ }^{21}$ The only case when up-front equity may be important is one where the firms' total values are exactly equal (see Miglo and Zenkevich, in press), keeping cash is not costly and the firm is prohibited from distributing first-period dividends. Then $I$ will not be mimicked by $S$ if it plays up-front equity. This scenario is unrealistic.
} 
The focus is on the analysis of separating equilibria and the link between firms' operating performance and financing strategies. It is shown that a separating equilibrium exists where firms with a higher rate of earnings growth issue less equity and more debt than firms with a stagnating profile. Thus, the model predicts that: 1) firms issuing equity underperform in the long run; 2) these firms have superior performance in the near future after the issue and; 3) there is a negative correlation between debt and profitability. According to Ritter and Welch (2002) long-term underperformance is one of the most intriguing phenomena in corporate finance. This paper has brought forth some new results which have not been tested in existing literature. Long-term operating underperformance of firms issuing equity should be more frequently observed when: 1) reorganization costs increase (Proposition 2) and; 2) asymmetric information regarding the timing of cash flows is larger than that regarding the total cash flows (Proposition 3).

\section{Appendix}

Proof of Lemma 1. Consider strategy $e$ played by type $x, x \in i, s$. Denote the dividend per share in period 1 when the cash flow is $r_{x 1}$ by $d_{x 1}^{r_{x 1}}$ and the total dividend in period 1 by $D_{x 1}^{r_{x 1}}$. Respectively $d_{x 2}^{r_{x 1} r_{x 2}}$ and $D_{x 2}^{r_{x 1} r_{x 2}}$ denote the dividend per share (total dividend) paid in period 2 when first-period earnings are $r_{x 1}$ and second-period earnings are $r_{x 2}$. The following equations determine the prices of issued securities:

1) budget constraint for equity issue:

$$
b=p_{x} \Delta n_{x}
$$

2) market valuation of shares (share price equals the expected amount of dividends per share):

$$
p_{x}=E_{r_{x 1}}\left[d_{x 1}^{r_{1}}+E_{r_{x 2}} d_{x 2}^{r_{1} r_{2}}\right]
$$

3) total dividend in period $t$ :

$$
\begin{gathered}
D_{x 1}^{r_{1}}=d_{x 1}^{r_{1}}\left(n+\Delta n_{x}\right) \\
D_{x 2}^{r_{1} r_{2}}=d_{x 2}^{r_{1} r_{2}}\left(n+\Delta n_{x}\right)
\end{gathered}
$$

4) earnings distribution in period $t$ :

$$
\begin{gathered}
D_{x 1}^{r_{1}}+f_{x}^{r_{1}}=r_{x 1} \\
D_{x 2}^{r_{x 1} r_{x 2}}=\max \left\{r_{x 2}-F_{x 2}^{r_{x 1}}, 0\right\}
\end{gathered}
$$

5) market valuation of second-period debt:

$$
b-f_{x}^{r_{x 1}}=E_{r_{x 2}} \min \left\{r_{x 2}, F_{x 2}^{r_{x 1}}\right\}
$$

Substituting (22)-(25) into (21) produces:

$$
p_{x}=\frac{E_{r_{x 1}}\left[r_{x 1}-f_{x}^{r_{x 1}}+E_{r_{x 2}} \max \left\{r_{x 2}-F_{x 2}^{r_{x 1}}, 0\right\}\right]}{n+\Delta n_{x}}
$$


Further using the identity $\max \left\{r_{x 2}-F_{x 2}^{r_{x 1}}, 0\right\}+\min \left\{r_{x 2}, F_{x 2}^{r_{x 1}}\right\}=r_{x 2}$ and (26) we get:

$$
p_{x}=\frac{E_{r_{x 1}}\left[r_{x 1}-f_{x}^{r_{x 1}}+E_{r_{x 2}}\left[r_{x 2}-\left(b-f_{x}^{r_{x 1}}\right)\right]\right]}{n+\Delta n_{x}}=\frac{\theta_{x 1}+\theta_{x 2}-b}{n+\Delta n_{x}}
$$

This equation together with (20) produces:

$$
p_{x}=\left(\theta_{x 1}+\theta_{x 2}-2 b\right) / n
$$

Also from (25):

$$
F_{x 2}^{r_{x 1}}=\left(b-f_{x}^{r_{x 1}}\right) / \theta_{x 2}
$$

Now consider strategy $d$. If $r_{x 1}=0$ then $V_{x 2}=\theta_{x 2}-b$ and $V_{x 2}^{c}=\gamma\left(\theta_{x 2}-b\right)$. First consider the case

$$
F_{x 1}>\theta_{x 2}-b
$$

We have:

6) market valuation of first-period debt:

$$
b=E_{r_{x 1}}\left[\min \left\{r_{x 1}, F_{x 1}\right\}+\gamma \operatorname{Pr}\left(r_{x 1}<F_{x 1}\right) E_{r_{x 2}} D_{x 2}^{0 r_{x 2}}\right]
$$

Equation (30) takes into account that if first-period cash flow is not sufficient to pay short-term debt the creditors get the fraction $\gamma$ of the firm's equity.

7) market valuation of second-period debt:

$$
b-f_{x}^{r_{x 1}}=E_{r_{x 2}} \min \left\{r_{x 2}, F_{x 2}^{r_{x 1}}\right\}
$$

Equation (30) can be written as

$$
b=\theta_{x 1} F_{x 1}+\left(1-\theta_{x 1}\right) \gamma E_{r_{x 2}} \max \left\{r_{x 2}-F_{x 2}^{0}, 0\right\}
$$

Using (31), $f_{x}^{0}=0$ and the identity:

$$
\max \left\{r_{x 2}-F_{x 2}^{r_{x 1}}, 0\right\}+\min \left\{r_{x 2}, F_{x 2}^{r_{x 1}}\right\}=r_{x 2}
$$

we get:

$$
E_{r_{x 2}} \max \left\{r_{x 2}-F_{x 2}^{0}, 0\right\}=\theta_{x 2}-b
$$

(32) and (33) imply

$$
F_{x 1}=\frac{b-\gamma\left(1-\theta_{x 1}\right)\left(\theta_{x 2}-b\right)}{\theta_{x 1}}
$$

(34) implies that if $\theta_{x 2}<2 b$, condition (29) holds. If $\theta_{x 2} \geq 2 b$ then $F_{x 1}=b$ (debt is risk-free). If $r_{x 1}=0$ then debt can be rolled over by issuing a new claim with a face value $F_{x}^{r}=b / \theta_{x 2}$. Since $\theta_{x 2} \geq 2 b$ the firm will be able to finance the second stage by issuing a new claim with a face value $F_{x 2}^{0}=b / \theta_{x 2}$.

Strategy $l$. There is no default in $t=1$. If long-term debt is junior then the firm distributes as much cash in dividend as possible in $t=1$ and borrows $b$ in the second period. Then we have: 
8) value of long-term debt:

$$
b=E_{r_{x 2}} \min \left\{\hat{r}_{2}, F_{x 2}\right\}
$$

where $\hat{r}_{2}$ denotes the funds remaining after the payment to second-period debtholders: $\hat{r}_{2}=\max \left\{r_{x 2}-F_{x 2}^{r_{x 1}}, 0\right\}$. Also:

9) market valuation of second-period debt:

$$
b=E_{r_{x 2}} \min \left\{r_{x 2}, F_{x 2}^{r_{x 1}}\right\}
$$

Which implies: $F_{x 2}^{r_{x 1}}=b / \theta_{x 2}$. (35) can be rewritten as $b=\theta_{x 2}\left(1-b / \theta_{x 2}\right)$ if $1-b / \theta_{x 2} \leq F_{x 2}$ and $b=\theta_{x 2} F_{x 2}$ if $1-b / \theta_{x 2}>F_{x 2}$. The latter implies $F_{x 2}=b / \theta_{x 2}$ and $\theta_{x 2}>2 b$ and the former gives $\theta_{x 2}=2 b$ and $F_{x 2} \geq 1 / 2$. In the latter case $F_{x 2}$ does not matter as long as $F_{x 2} \geq 1 / 2$ (long-term creditors capture all residual earnings after the payment to the second-period creditors) and thus we can assume $F_{x 2}=1 / 2=b / \theta_{x 2}$. Finally, strategy $l$ is only possible if $\theta_{x 2} \geq 2 b$ and $F_{x 2}=b / \theta_{x 2}$.

If long-term debt is senior and $\theta_{x 2} \geq 2 b$ then we have $1 \geq F_{x 2}+F_{x 2}^{0}$ where $F_{x 2}=b / \theta_{x 2}$ and $F_{x 2}^{0}=b / \theta_{x 2}$. The debtholders' payoff does not depend on first-period earnings (which will be distributed in total to the shareholders) but only on second-period earnings. If $r_{x 2}=1$ they are paid in full, otherwise they get nothing. If $\theta_{x 2}<2 b$ then if $r_{x 1}=0$ the firm is not able to finance the second stage externally and thus the entrepreneur offers the creditors a claim with a real value equal to 0 . The creditors will accept the offer because if they do not, they will not have a legal right to appeal in contrast to the short-term debt scenario, and the firm will not finance the second stage. Finally if $\theta_{x 2}<2 b$ financing with long-term debt is impossible.

Proof of Lemma 2. Obviously $\theta_{i 1} \geq \theta_{s 1}$ implies $\theta_{i 2}>\theta_{s 2}$ by (1). By Lemma 1, any claim issued by $i$ has a higher value than that of type $s$, meaning that $s$ will always mimic $i$ (if they play a different strategy) and a separating equilibrium does not exist. Now $\theta_{s 2} \geq \theta_{i 2}$ implies $\theta_{s 1}>\theta_{i 1}$ and we have the same situation as above, except that now the roles are reversed: $i$ mimics $s$. End proof.

Proof of Corollary 1. If $\theta_{i 1} \geq \theta_{s 1}$ then by Lemma 2 a separating equilibrium does not exist. Consider $\theta_{i 1}<\theta_{s 1}$. Then, by the definition of $g$ and from $g_{i}=g_{s}$ we have $\theta_{i 2}<\theta_{s 2}$. By Lemma 2, a separating equilibrium does not exist. End proof.

Proof of Lemma 3. Using (2), (5), Lemma 1 and the following identity:

$$
\frac{\partial R_{k m}^{e}}{\partial v_{m}}=\frac{\partial R_{k m}^{e}}{\partial \theta_{m 1}} \frac{\partial \theta_{m 1}}{\partial v_{m}}+\frac{\partial R_{k m}^{e}}{\partial \theta_{m 2}} \frac{\partial \theta_{m 2}}{\partial v_{m}}
$$

we get:

$$
\begin{gathered}
\frac{\partial R_{k m}^{e}}{\partial v_{m}}=\frac{b}{\left(v_{m}-b\right)^{2}}\left[\theta_{k 1}\left(1-f_{k}^{1}+\theta_{k 2}\left(1-F_{m 2}^{1}\right)\right)+\left(1-\theta_{k 1}\right) \theta_{k 2}\left(1-F_{m 2}^{0}\right)\right]+ \\
+\frac{\alpha_{m 1} \theta_{k 2} g_{m}\left(b-\theta_{k 1} f_{k}^{1}\right)}{\left(1+g_{m}\right) \theta_{m 2}^{2}}>0
\end{gathered}
$$


(the first term is strictly positive and the second term is non-negative because $\left.\theta_{k 1} f_{k}^{1} \leq f_{k}^{1} \leq b\right)$. The proof is analogous for the rest of the Lemma (all parts of proofs, omitted for brevity, are available upon demand). End proof.

Proof of Lemma 4. Using (2), (5), Lemma 1 and the following identity:

$$
\frac{\partial R_{k m}^{e}}{\partial g_{m}}=\frac{\partial R_{k m}^{e}}{\partial \theta_{m 1}} \frac{\partial \theta_{m 1}}{\partial g_{m}}+\frac{\partial R_{k m}^{e}}{\partial \theta_{m 2}} \frac{\partial \theta_{m 2}}{\partial g_{m}}
$$

we get: $\frac{\partial R_{k m}^{e}}{\partial g_{m}}=\frac{\alpha_{m 1} v_{m}\left(b-\theta_{k 1} f_{k}^{1}\right)}{\left(1+g_{m}\right)^{2} \theta_{m 2}^{2}}>0$

This is strictly positive because $\theta_{k 1} f_{k}^{1} \leq f_{k}^{1} \leq b$ and if $k=i$ then by (14) $\theta_{k 1}=\theta_{i 1}<\theta_{s 1} \leq 1$ and if $k=s$ then $f_{k}^{1}=f_{s}^{1}=0$. End proof.

Proof of Proposition 1. Suppose that a separating equilibrium exists where $i$ plays equity. Then the following should hold:

$$
R_{s i}^{e} \leq 0
$$

Also:

$$
R_{s i}^{e} \equiv R^{e}\left(v_{s}, g_{s}, v_{i}, g_{i}, b, \gamma\right)>R^{e}\left(v_{s}, g_{s}, v_{s}, g_{s}, b, \gamma\right) \equiv R_{s s}^{e}=0
$$

This inequality follows from Lemmas 3 and 4 , the continuity of $R^{e}(),.(15)$ and (16). From (38) the condition (36) cannot be true. End proof.

Proof of Lemma 5. Since $\theta_{i 2}<2 b$ we have from (6) and (7):

$$
\frac{\partial R_{s i}^{d}}{\partial \gamma}=\frac{\left(\theta_{i 2}-b\right)\left(\theta_{s 1}\left(1-\theta_{i 1}\right) \theta_{i 2}-\theta_{i 1} \theta_{s 2}\left(1-\theta_{s 1}\right)\right)}{\theta_{i 1} \theta_{i 2}}
$$

This is positive by (14). End proof.

Proof of Corollary 2. Lemma 5 implies that three situations are possible.

1. There exists $\bar{\gamma} \in[0,1]$ such that $R_{s i}^{d}\left(\gamma^{*}\right)=0$. Then let $\gamma^{*}=\bar{\gamma}$. Corollary 2 follows from Lemma 5 .

2. $R_{s i}^{d}<0$ for any $\gamma \in[0,1]$. Then let $\gamma^{*}=1$.

3. $R_{s i}^{d}>0$ for any $\gamma \in[0,1]$. End proof.

Proof of Proposition 2. First note that (19) holds by Lemmas 3 and 4. We have

$$
R_{i s}^{e} \equiv R^{e}\left(v_{i}, g_{i}, v_{s}, g_{s}, b, \gamma\right)<R^{e}\left(v_{i}, g_{i}, v_{i}, g_{i}, b, \gamma\right) \equiv R_{i i}^{e}=0
$$

This inequality follows from Lemma 3 and 4 , the continuity of $R^{e}(),.(15)$ and (16). Secondly consider (18). By Corollary 2 it holds if and only if $\gamma^{*}$ exists and $\gamma \leq \gamma^{*}$. End proof.

Proof of Lemma 6. Part 1. From (6) and (7) we have: $\frac{\partial R_{s i}^{d}}{\partial g_{s}}=\frac{v_{s}\left(A+B g_{s}\right)}{\left(1+g_{s}\right)^{3}}$ where

$$
\begin{gathered}
A=\frac{b\left(\theta_{i 2}-\theta_{i 1}\right)-\gamma\left(\theta_{i 2}-b\right)\left(\left(1-v_{s}\right) \theta_{i 1}+\left(1-\theta_{i 1}\right) \theta_{i 2}\right)}{\theta_{i 1} \theta_{i 2}} \\
B=-\frac{\gamma\left(\theta_{i 2}-b\right)\left(1+v_{s}\right)}{\theta_{i 2}}<0
\end{gathered}
$$


( $A$ and $B$ are both independent of $g_{s}$ ). From (1) and the definition of $g_{s}$ we have: $g_{s} \in\left[b, g_{i}\right]$. Three situations are possible.

1. $b \leq-A / B \leq g_{i}$. Then $\frac{\partial R_{s i}^{d}}{\partial g_{s}} \geq 0$ if $-A / B>g_{s}$ and $\frac{\partial R_{s i}^{d}}{\partial g_{s}} \leq 0$ if $-A / B<g_{s}$. Also $R_{s i}^{d}>0$ when $g_{s}=g_{i}$ by Lemma 2 and (16). Then either $R_{s i}^{d}>0$ for any $g_{s}$ or there exists $g_{s}^{*} \in\left[b, g_{i}\right]$ such that $R_{s i}^{d}>0$ if and only if $g_{s}^{*}<g_{s}$.

2. $b>-A / B$. Then $\frac{\partial R_{s i}^{d}}{\partial g_{s}}<0$ for any $g_{s}$ which implies (because $R_{s i}^{d}>0$ when $g_{s}=g_{i}$ ) that $R_{s i}^{d}>0$ for any $g_{s}$.

3. $-A / B>g_{i}$. Then $\frac{\partial R_{s i}^{d}}{\partial g_{s}}>0$ for any $g_{s}$. Again either $R_{s i}^{d} \geq 0$ for any $g_{s}$ or there exists $g_{s}^{*} \in\left[b, g_{i}\right]$ such that $R_{s i}^{d}>0$ if and only if $g_{s}^{*}<g_{s}$.

Part 2. From (6) we have:

$$
\frac{\partial R_{s i}^{d}}{\partial v_{s}}=\frac{\theta_{i 2}\left(\gamma\left(\theta_{i 2}-b\right)-b\right)+\gamma \theta_{i 1}\left(\theta_{i 2}-b\right)\left(\theta_{s 2}-\theta_{i 2}\right)+g_{s} \theta_{i 1}\left(\gamma\left(\theta_{i 2}-b\right)\left(\theta_{s 1}-1\right)-b\right)}{\theta_{i 1} \theta_{i 2}\left(1+g_{s}\right)}<0
$$

(the second term is obviously strictly negative and the first term is strictly negative because $\theta_{i 2}<2 b, \gamma \leq 1$ and $\left.\theta_{s 2}<\theta_{i 2}\right)$. The rest of lemma follows from this inequality. End proof.

Proof of Proposition 3. From our previous proofs (19) holds. From the first part of Lemma 6, (18) holds if and only if $g_{s} \leq g_{s}^{*}$ (other parameters being equal). The second part of proposition 3 follows from the second part of Lemma 6. End proof.

Proof of Proposition 4. Suppose that a separating equilibrium exists where $i$ plays long-term debt. From (14) and Lemma 1 the claims issued by type $i$ have higher value than the symmetric information value of claims issued by type $s$. Thus $s$ will mimic $i$. End proof.

Proof of Proposition 5.

Lemma 7. If information is symmetric then:

$$
\begin{gathered}
p_{x}=\left(\theta_{x 1}+\theta_{x 2}-2 b\right) / n=\left(r_{x}-2 b\right) / n \\
F_{x 1}=\left\{\begin{array}{c}
\frac{b_{e}-\gamma\left(1-\theta_{x 1}\right)\left(\theta_{x 2}-b\right)}{\theta_{x 1}}, \theta_{x 2}<b+b_{e} \\
b, \theta_{x 2} \geq b+b_{e}
\end{array}\right. \\
F_{x 2}^{r_{x 1}}=\left(b-f_{x}^{r_{1}}\right) / \theta_{x 2} \\
F_{x}^{r}=\gamma\left(\theta_{x 2}-b\right) / \theta_{x 2}
\end{gathered}
$$

Proof of Lemma 7 is omitted for brevity (similar to that of Lemma 1).

Proof of Lemma 8. If the firm is perceived by the market as type $i$ then the prices of securities are equal to the symmetric information prices for type $i$. If $b_{d}>0$ and $b_{d}>\theta_{i 2}-b$ then

$$
V_{s i}\left(b_{e}\right)=\alpha_{i 1}\left[\theta_{s 1}\left(1-F_{i 1}+\theta_{s 2}\left(1-b / \theta_{i 2}\right)\right)+\left(1-\theta_{s 1}\right)(1-\gamma) \theta_{s 2}\left(1-b / \theta_{i 2}\right)\right]
$$

where

$$
\alpha_{i 1}=\frac{\theta_{i 1}+\theta_{i 2}-2 b}{\theta_{i 1}+\theta_{i 2}-2 b+b_{e}}
$$




$$
F_{i 1}=\frac{b_{d}-\gamma\left(1-\theta_{i 1}\right)\left(\theta_{i 2}-b\right)}{\theta_{i 1}}
$$

Thus

$$
\frac{\partial V_{s i}\left(b_{e}\right)}{\partial b_{e}}=\frac{\left(\theta_{i 2}-b\right)\left(\theta_{s 1} \theta_{i 2}-\theta_{i 1} \theta_{s 2}-\gamma\left(\theta_{s 1} \theta_{i 2}\left(1-\theta_{i 1}\right)-\theta_{i 1} \theta_{s 2}\left(1-\theta_{s 1}\right)\right)\right.}{\theta_{i 1} \theta_{i 2}}
$$

By (14), this expression attains its minimum when $\gamma=1$ and it is

$\frac{\left(\theta_{i 2}-b\right) \theta_{s 1}\left(\theta_{i 2}-\theta_{s 2}\right)}{\theta_{i 2}}>0$. The proof is analogous for the second part. End proof.

Lemma 9. If an equilibrium exists where $i$ plays $b_{e}$ and $s$ plays $b_{e}^{\prime}$ and $b_{e}>b_{e}^{\prime}$ then there is also an equilibrium where $i$ plays $b_{e}^{\prime}$ and $s$ plays $b_{e}$.

Proof. Suppose that a separating equilibrium where $i$ plays $b_{e}$ and $s$ plays $b_{e}^{\prime}$ exists and that $b_{e}>b_{e}^{\prime}$. If $b_{d}=b-b_{e}>0$ and $\theta_{i 2}-b \geq b_{d}$ then by Lemma 7 all claims issued by type $i$ have a higher value than those of type $s$ and thus a separating equilibrium is impossible. If $b_{d}=0$ then a separating equilibrium does not exist (analogous to Proposition 4). We thus consider the case $b_{d}>0$ and $\theta_{i 2}-b<b_{d}$. Since no type has an incentive to mimic another type we have:

$$
\begin{aligned}
& V_{i s}\left(b_{e}^{\prime}\right) \leq \theta_{i 1}+\theta_{i 2}-2 b \\
& V_{s i}\left(b_{e}\right) \leq \theta_{s 1}+\theta_{s 2}-2 b
\end{aligned}
$$

By Lemma 8

$$
V_{s i}\left(b_{e}^{\prime}\right) \leq V_{s i}\left(b_{e}\right)
$$

From (42) and (43) we have:

$$
V_{s i}\left(b_{e}^{\prime}\right) \leq \theta_{s 1}+\theta_{s 2}-2 b
$$

Analogously we get

$$
V_{i s}\left(b_{e}\right) \leq \theta_{i 1}+\theta_{i 2}-2 b
$$

(44) and (45) prove the existence of equilibrium where $i$ plays $b_{e}^{\prime}$ and $s$ plays $b_{e}$. End proof.

Now we turn to the proof of Proposition 5 . Let $\Xi_{1}$ contain all equilibriums such as: 1) if $i$ plays $b_{e}$ and $s$ plays $b_{e}^{\prime}$ then $\left.b_{e}<b_{e}^{\prime} ; 2\right)$ an equilibrium where $i$ plays $b_{e}^{\prime}$ and $s$ plays $b_{e}$ does not exist. Let $\Xi_{2}$ contain all other separating equilibriums. $\Xi_{1}$ obviously satisfies the conditions described in the proposition. Now consider an equilibrium from $\Xi_{2}$ where $i$ plays $b_{e}$ and $s$ plays $b_{e}^{\prime}$. If $b_{e}<b_{e}^{\prime}$ then from above there is also an equilibrium in $\Xi_{2}$ where $i$ plays $b_{e}^{\prime}$ and $s$ plays $b_{e}$ which proves the proposition. The same is also true if $b_{e}>b_{e}^{\prime}$ by Lemma 9 . End proof.

Proof of Proposition 6. Sufficiency. It obviously follows from propositions 2 and 3: an equilibrium where $i$ issues only debt and $s$ issues only equity exists and it belongs to $\Xi_{1}$. Necessity. Suppose that the conditions of propositions 2 and 3 do not hold and $\Xi_{1}$ is non-empty. Thus a separating equilibrium exists. Then by Lemma 8 there also exists a separating equilibrium where $i$ issues only debt 
and $s$ issues only equity which contradicts the assumption that the conditions of propositions 2 and 3 do not hold. End proof.

\section{References}

Baker, M., and J. Wurgler. 2002. "Market Timing and Capital Structure". Journal of Finance 57, 1-32.

Berkovitch, E., and M. Narayanan. 1993. "Timing of Investment and Fi-

nancing Decisions in Imperfectly Competitive Financial Markets". Journal of Business 66, 219-248.

Butler, A., G. Grullon and J. Weston. 2005. "Can Managers Forecast Aggregate Market Returns?". Journal of Finance 60, 963-986.

Brennan, M. and A. Kraus. 1987. "Efficient Financing under Asymmetric Information". Journal of Finance 42, 1225-1243.

Brick, I., M. Frierman, and Y. K. Kim. 1998. "Asymmetric Information Concerning the Variance of Cash Flows: The Capital Structure Choice". International Economic Review 39, 745-761.

Cai, J., and T. Loughran. 1998. "The Performance of Japanese Seasoned Equity Offerings, 1971-1992". Pacific-Basin Finance Journal 6, 395-426.

Cai, J., and K. Wei. 1997. "The Investment and Operating Performance of Japanese Initial Public Offerings". Pacific-Basin Finance Journal 5, 389-417.

Degeorge, F., Patel, J., and Zeckhauser, R. 1999. "Earnings Management to Exceed Thresholds". Journal of Business 72, 1-33.

Diamond, D. 1991. "Debt Maturity Structure and Liquidity Risk". Quarterly Journal of Economics 106, 709-737.

Eckbo, B.E., R. Masulis, and O. Norli. 2000. "Seasoned Public Offerings: Resolution of the 'New issues Puzzle"'. Journal of Financial Economics 56, 251-291.

Eckbo, B.E., and O. Norli. 2001. "Leverage, Liquidity and Long-run IPO Returns". working paper, Tuck School of Business, Dartmouth College, NH.

Flannery M. 1986. "Asymmetric Information and Risky Debt Maturity Choice". Journal of Finance 41, 19-37.

Giammarino, R. 1989. "The Resolution of Financial Distress", Review of Financial Studies 2, 25-47.

Giammarino, R., and E. Neave. 1982. "The Failure of Financial Contracts and the Relevance of Financial Policy". Queen's University, School of Business, Working paper \#82-3.

Goswami, G., T. Noe, and M. Rebello. 1995. "Debt Financing under Asymmetric information". Journal of Finance 50, 633-659.

Grinblatt, M. and C. Y. Hwang. 1989. "Signalling and the Pricing of New Issues". Journal of Finance 44, 393-420.

Hennessy, C., and T. Whited. 2005. "Debt Dynamics". Journal of Finance 60, 1129-1165.

Jain, B., and O. Kini, 1994. "The Post-Issue Operating Performance of IPO Firms". Journal of Finance 69, 1699- 1726.

Jensen, M. 1986. "Agency Costs and Free Cash Flow, Corporate Finance and Takeovers". American Economic Review 76, 659-665. 
Jensen, M., and W. Meckling. 1976. "Theory of the Firm: Managerial Behavior, Agency Costs and Ownership Structure". Journal of Financial Economics 3, 305-360.

Korajczyk, R.A, D.J. Lucas, and R.L. McDonald (1992): "Equity Issues with Time Varying Asymmetric Information". Journal of Financial and Quantitative Analysis 27, 397-417.

Loughran, T., and J. Ritter. 1997. "The Operating Performance of Firms Conducting Seasoned Equity Offerings". Journal of Finance 52, 1823-1850.

Lucas, D., and R. McDonald. 1990. "Equity Issues and Stock Price Dynamics". Journal of Finance 45, 1019-1043.

Mickelson, W., M. Partch, and K. Shah. 1997. "Ownership and Operating Performance of Companies that go public". Journal of Financial Economics 44, 281-307.

Miglo, A., and N. Zenkevich. 2006. "Non-hierarchical Signalling: Two-stage Financing Game". University of Guelph working paper 2006-3.

Miglo, A., and N. Zenkevich. (in press). "Non-hierarchical Signalling: Twostage Financing Game". International Journal of Mathematics, Game Theory and Algebra 15 (3). Reprinted in Game Theory and Applications: Volume 11. NY: Nova Science Publishers Inc.(forthcoming).

Myers, S. 1977. "Determinants of Corporate Borrowing". Journal of Financial Economics 5, 147-176.

Myers, S. 1984. "The Capital Structure Puzzle". Journal of Finance 39, 575-592.

Myers, S., and N. Majluf. 1984. "Corporate Financing and Investment Decisions When Firms Have Information That Investors Do not have". Journal of Financial Economics 13, 187-221.

Nachman, D. C., and T. H. Noe. 1994. "Optimal Design of Securities under Asymmetric information". The Review of Financial Studies, 1, 1-44.

Pagano, M., F. Panetta, and L. Zingales. 1998. "Why Do Companies Go Public? An Empirical Analysis". Journal of Finance 53, 27-64.

Purnanandam, A., and B. Swaminathian. 2004. "Are IPOs underpriced?". Review of Financial Studies 17, 811- 848.

Rajan, R. G., and L. Zingales. 1995. "What do we know about Capital Structure? Some Evidence from International Data". Journal of Finance 50, 1421-1460.

Ritter, J., and I. Welch. 2002. "A Review of IPO Activity, Pricing and Allocations". Journal of Finance 57, 1795-1828.

Schultz, P. 2003. "Pseudo Market Timing and the Long-run Underperformance of IPOs". Journal of Finance 58, 483-517.

Stein, J. 1989. "Efficient Capital Markets, Inefficient Firms: A Model of Myopic Corporate Behavior". Quarterly Journal of Economics 104, 655-669

Teoh, S., I. Welch and T. Wong. 1998. "Earnings Management and the Long-run Market Performance of Initial Public Offerings". Journal of Finance 53, 1935-1974.

Titman, S., and R. Wessels. 1988. "The Determinants of Capital Structure Choice". Journal of Finance 43, 1-19. 
Zwiebel, J. 1996. "Dynamic Capital Structure under Managerial Entrenchment". American Economic Review 86, 1197-1215. 